Article

\title{
Phase Stability and Microstructure Evolution of Solution-Hardened 316L Powder Feedstock for Thermal Spraying
}

\author{
Thomas Lindner*, Martin Löbel and Thomas Lampke (1) \\ Materials and Surface Engineering Group, Institute of Materials Science and Engineering, Chemnitz University \\ of Technology, D-09107 Chemnitz, Germany; martin.loebel@mb.tu-chemnitz.de (M.L.); \\ thomas.lampke@mb.tu-chemnitz.de (T.L.) \\ * Correspondence: th.lindner@mb.tu-chemnitz.de; Tel.: +49-371-531-38287
}

Received: 4 December 2018; Accepted: 13 December 2018; Published: 14 December 2018

check for updates

\begin{abstract}
A solution-hardening of AISI 316L stainless-steel powder was conducted. The expansion of the crystal lattice and a strong increase in the nanoindentation hardness confirm the successful diffusion of carbon and nitrogen in the interstices. A multiphase state of the powder feedstock with phase fractions of the metastable S-phase (expanded austenite) mainly at the particle's edge, and the initial austenitic phase within the core was found. Thermal spraying using high velocity oxy-fuel (HVOF) and atmospheric plasma spraying (APS) prove the sufficient thermal stability of the S-phase. Microstructural investigations of the HVOF coating reveal the ductility of the S-phase layer, while the higher heat load within the APS cause diffusion processes with the initial austenitic phase. The lattice expansion and the nanoindentation hardness decrease during thermal spraying. However, the absence of precipitates ensures the sufficient heat stability of the metastable S-phase. Even though further efforts are required for the thermochemical treatment of powder feedstock, the results confirm the feasibility of the novel powder treatment approach.
\end{abstract}

Keywords: thermal spraying; HVOF; APS; S-phase; expanded austenite; 316L; stainless steel; thermochemical treatment; hardening; gas nitrocarburization

\section{Introduction}

The corrosion resistance of austenitic stainless steel has contributed to the wide range of high-performance applications of this material group. Despite their excellent corrosion resistance, the low wear resistance restricts possible applications. Surface hardening by thermochemical treatment is suitable to enhance the material's performance. In contrast to precipitation hardening, the interstitial solvation of carbon and nitrogen enables the retention of corrosion resistance, because of the absence of chromium depletion [1-4]. The interstitial solvation causes an expansion of the lattice and the formation of compressive stresses [5,6]. Consequently, an enhancement of the properties with a significant increase of hardness and wear resistance can be achieved, which prevents premature failure under superimposed loading. Most of the hardening techniques for stainless-steel have been developed for wrought materials. However, recent publications prove the possibility of adapting these processes for coatings [7-12]. Producing coatings by thermal spraying can be used for various substrate materials, because of their comparatively low heat load. Furthermore, the limited thermal stress efficiently prevents the formation of precipitates of the metastable S-phase, and enable repair applications of worn surface parts. A successful S-phase formation of the thermal spray coatings by thermochemical post-treatment was first reported by Wielage et al. [7]. Further investigations by Adachi et al. and Lindner et al. prove the general feasibility of coating treatment by low-temperature thermochemical 
processes [4,8-12]. In comparison to the thermochemical treatment of wrought material, an increase in the diffusion depth caused by structure penetration was achieved for gaseous enrichment media [11]. A significant expansion of the lattice parameter occurred for the face-centered cubic (fcc) phase, in accordance with thermochemical treated wrought material [7,11]. Lindner et al. proved that the surface activation step that is usually carried out to dissolve the diffusion barrier layer of wrought material can be omitted for the thermochemical treatment of AISI 316L high velocity oxy-fuel (HVOF) coatings [12]. However, an additional thermochemical post-treatment step is still required to form an S-phase layer in the repair coatings. Especially for the restoring of large components, a possible cost benefit can be achieved by omitting the additional step.

A new approach for the enhancement of coating properties is the direct thermochemical treatment of the thermal-spraying feedstock. Different approaches for the nitriding of steel powder have been investigated $[13,14]$. However, no successful formation of an S-phase in austenitic steel powder has been achieved yet. In the present study, precipitation-free hardening by interstitial solvation of carbon and nitrogen was conducted for the feedstock, in order to provide sufficient ductility. Because of the limitations in diffusion depth, a complete S-phase formation with an expanded austenitic lattice is only possible for powder feedstock with a maximum particle size of $60 \mu \mathrm{m}$. This criterion is fulfilled for most of the commonly used thermal-spraying powder fractions. In addition to a successful phase formation in the powder pre-treatment, the phase stability within the thermal-spraying process is of major importance. The stability of the S-phase greatly depends on the duration time of the temperature exposure $[15,16]$. The temperature-time profile of the thermochemical treatment has to be adjusted for each alloy system to avoid precipitations during S-phase formation. Regarding the thermal-spraying process, the influence of a comparable short-term temperature load on phase stability has not been investigated yet. However, apart from low-temperature treatment, the S-phase can be formed by high-temperature processes above the solvation temperature of precipitates [17]. Precipitates can be avoided by quenching after the thermochemical treatment [18]. The thermal stability of the S-phase in the thermal-spraying processes needs to be investigated.

This feasibility study focusses on general issues regarding the temperature dependency of S-phase stability. Low-temperature gas nitrocarburized (GNC) powder feedstock was processed by HVOF and atmospheric plasma spraying (APS). These processes provide the full range of the typical temperature-time exposure of the thermal-spraying processes, resulting in a different degree of melting. The present article contributes to an improved understanding of S-phase characteristics, in conjunction with temperature exposure during thermal spraying.

\section{Materials and Methods}

Gas-atomized AISI 316L powder with a specified particle size of $-53+20 \mu \mathrm{m}$ was used. The particle size distribution was examined by laser diffraction analysis in a Cilas 930 device (Cilas, Orléans, France). In order to obtain an expanded austenitic-phase modification by interstitial diffusion enrichment, a low-temperature gas nitrocarburization treatment was conducted at a temperature below $450{ }^{\circ} \mathrm{C}$, with a duration time of $30 \mathrm{~h}$. Because of the low weight of the powder particles, the risk of whirling within the gas flow increases. Therefore, the powder was given into a vessel up to a fill-level of $50 \mathrm{~mm}$, and a static thermochemical treatment was performed. Thermal spraying was performed on stainless-steel AISI 316L substrates. The bar material with a diameter of $40 \mathrm{~mm}$ was sliced in discs with a thickness of $8 \mathrm{~mm}$. The substrates were pre-treated by corundum blasting using Alodur EK-F 24 (Treibacher Industrie AG, Althofen, Austria), a pressure of 3 bar, a distance of $200 \mathrm{~mm}$, and an angle of $70^{\circ}$. Subsequently, the substrates were cleaned in an ultrasonic ethanol bath for $10 \mathrm{~min}$. For the coating process, the HVOF K2 and the APS F6 (GTV, Luckenbach, Germany) thermal-spraying systems were used, with the parameters summarized in Table 1. Two low-pressure disc powder feeders from the system PFW 4/3 S (GTV, Luckenbach, Germany) were used with standard discs (groove size $=19.2 \mathrm{~mm}^{2}$ ) and NL wipers for the powder supply. 
The surface of the coated samples was polished up to mesh 1000, resulting in a final coating thickness of approximately $270 \mu \mathrm{m}$. Metallographic cross-sections were prepared according to the standard metallographic procedures. For the visualization of different microstructural domains, the cross-sections were etched using a Beraha-II color etchant. The resulting contrast enables the evaluation of diffusion-enriched areas, regarding their presence and distribution. For the metallographic investigations, an optical microscope GX51 (Olympus, Shinjuku, Japan) equipped with a SC50 camera (Olympus, Shinjuku, Japan) was used. The chemical composition was measured by energy-dispersive X-ray spectroscopy (EDS) in the scanning electron microscope LEO 1455VP (Zeiss, Jena, Germany).

Table 1. The parameters of the thermal-spraying processes conducted with a high velocity oxy-fuel (HVOF) K2 and an atmospheric plasma spraying (APS) F6 system.

\begin{tabular}{|c|c|c|c|c|c|c|c|c|c|}
\hline $\begin{array}{c}\text { Spray } \\
\text { Process }\end{array}$ & $\begin{array}{c}\text { Kerosene/Oxygen } \\
\text { Flow Rate } \\
(1 / h)\end{array}$ & $\begin{array}{c}\text { Argon/Hydrogen } \\
\text { Flow Rate } \\
\text { (1/min) }\end{array}$ & $\begin{array}{c}\text { Current } \\
\text { (A) }\end{array}$ & $\begin{array}{c}\text { Spraying } \\
\text { Distance } \\
(\mathrm{mm})\end{array}$ & $\begin{array}{c}\text { Nozzle } \\
(\mathrm{mm})\end{array}$ & $\begin{array}{l}\text { Transverse } \\
\text { Speed } \\
(\mathrm{m} / \mathrm{s})\end{array}$ & $\begin{array}{l}\text { Offset } \\
(\mathrm{mm})\end{array}$ & $\begin{array}{l}\text { Powder } \\
\text { Feed Rate } \\
(\mathrm{g} / \mathrm{min})\end{array}$ & $\begin{array}{c}\text { Gas Feed } \\
\text { (Argon) } \\
(1 / \mathrm{min})\end{array}$ \\
\hline HVOF & $0.4 / 900$ & - & - & 350 & $150 / 14$ & 1 & 5 & 70 & $2 \times 8$ \\
\hline APS & - & $50 / 10$ & 600 & 140 & 6 & 1 & 5 & 76 & $2 \times 4$ \\
\hline
\end{tabular}

A phase selective hardness measurement was carried out by nanoindentation. For this, a nanoindenter UNAT (ASMEC GmbH, Radeberg, Germany) with a Berkovich tip was used for quasi-static measurement with a load of $1 \mathrm{mN}$. Phase analyses were conducted by X-ray diffraction (XRD) using a D8 DISCOVER diffractometer (Bruker AXS, Billerica, MA, USA) with Co-K $\alpha$ radiation (tube voltage: $40 \mathrm{kV}$; tube current: $40 \mathrm{~mA}$ ). The diffractometer was equipped with polycap optics for beam shaping, a $1 \mathrm{~mm}$ pinhole collimator, and a 1D Lynxeye XE (Bruker AXS, Billerica, MA, USA)

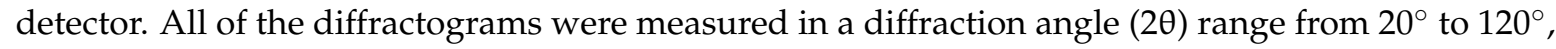
with a step size of $0.01^{\circ}$, and $1.5 \mathrm{~s} / \mathrm{step}$. Because of the use of the $1 \mathrm{D}$ detector, this value corresponds to $288 \mathrm{~s} / \mathrm{step}$. The powder diffraction file (PDF) database from 2014 was applied for the phase identification and for the determination of the lattice parameters.

In order to investigate the tribological behavior under abrasive wear conditions, scratch tests have been carried out using a CSM Revetest-RST device (CSM Instruments SA, Peseux, Switzerland). The applied parameters are summarized in Table 2. For the determination of the resulting wear depths, tactile measurements with a load of $0.9 \mathrm{~N}$ were carried out using the truncated diamond cone tip of the wear testing device. In addition, HVOF and APS coatings were produced with untreated powder as reference samples, with the parameters stated in Table 1.

Table 2. Wear test parameters.

\begin{tabular}{cc}
\hline & Scratch Test \\
\hline mode & progressive \\
force & $1-200 \mathrm{~N}$ \\
speed & $2.5 \mathrm{~mm} / \mathrm{min}$ \\
length & $5 \mathrm{~mm}$ \\
tip & truncated diamond cone \\
radius & $200 \mu \mathrm{m}$ \\
\hline
\end{tabular}

\section{Results}

\subsection{Powder Characterization}

The particle-size distribution of the powder is fundamental for the processing properties in thermal-spraying. The resulting deviation in the specific surface directly influences the interaction with the surrounding media. Hence, a wide range of thermal and kinetic state variables occur in the thermal-spraying process, depending on the particle-size distribution. Whereas the specific surface is doubled by halving the particle diameter, the mass is divided by an eighth. Therefore, a narrow 
particle-size distribution is intended to reduce fluctuations in state variables [19]. The particle-size distribution by weight of the AISI 316L powder in untreated state is shown in Figure 1.
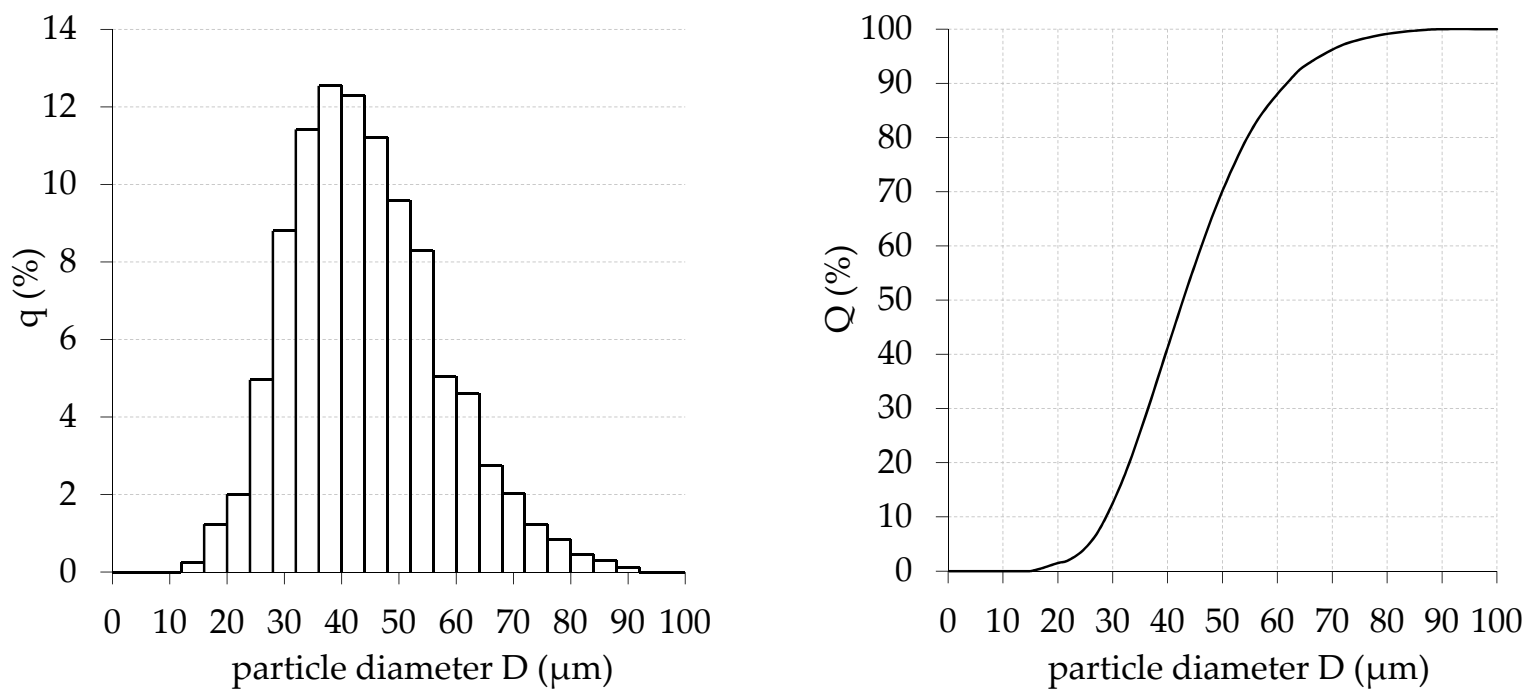

Figure 1. Measured particle sizes of the AISI 316L powder feedstock with frequency distribution $\mathrm{q}$ (left) and cumulative distribution $Q$ (right).

The histogram with a constant class width of $4 \mu \mathrm{m}$ shows a unimodal distribution, which is in good accordance with a Gaussian normal distribution. This is confirmed by a minor deviation between the mean and modal value, as seen in Table 3. The cumulative distribution enables the evaluation of the characteristic values, which are commonly used for the description of the powder feedstock. Typically, the powder fraction of the thermal-spraying feedstock is specified by the D10 and D90 limit values. Only a minor deviation with a slightly coarser particle fraction occurs in comparison to the specifications of the distributer. Nevertheless, nearly $90 \%$ of the powder mass fulfills the criterion of a particle size below $60 \mu \mathrm{m}$, which is required for the full formation of the expanded austenite. Hence, a sufficient suitability for processing using thermochemical treatment is proven.

Table 3. Characteristic particle size distribution values of the AISI 316L powder feedstock.

\begin{tabular}{cccccc}
\hline Parameter & D10 & D90 & D50 & D32 & Modal Value \\
\hline$\varnothing(\mu \mathrm{m})$ & 28.7 & 61.9 & 42.9 & 37.1 & 38.1 \\
\hline
\end{tabular}

The microstructural investigations of the powder cross-sections reveal a mainly spherical shape of the particles, as seen in Figure 2. Etching with Beraha-II visualizes a multiphase state comprising phase fractions of the metastable S-phase and the initial austenitic phase. Additionally, the EDS measurements prove a carbon-rich phase on the top of some single particles, which is deposited as an impurity during the hardening process. Whereas some particles exhibit a full S-phase formation, partial enrichment was observed for most of the particles. A partial S-phase formation is confirmed by the XRD measurements. In comparison with the untreated state, a lattice expansion of the austenitic phase occurs for the gas nitrocarburized powder (Figure 3). Because of the heterogeneous phase state, a broad shift area with no distinct peak appears. No distinct diffraction peaks of precipitates can be observed, showing that only interstitial solvation within the lattice occurs.

The heterogeneous diffusion enrichment indicates a limitation in the permeability of the donator, probably caused by a decrease in exchangeability within the cavities of the powder. Furthermore, the deposition of the carbon increases this effect. 

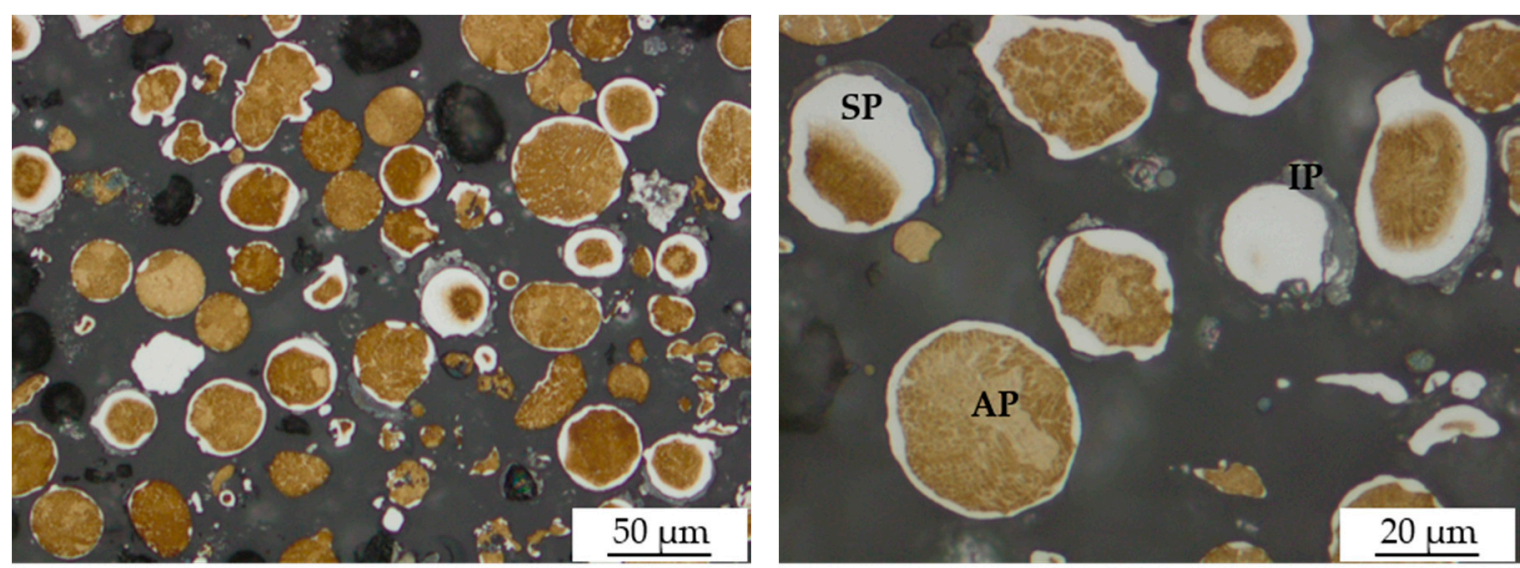

Figure 2. Optical-microscopic images of Beraha-II etched AISI 316L powder feedstock after gas nitrocarburization with low magnification (left) and detail view (right) with phase declaration (SP-S-phase; AP—austenitic phase; IP—impurity).

The S-phase is mainly formed at the particle's edge. This part is exposed to the heaviest thermal load during thermal spraying. Although the objective of a homogeneous diffusion enrichment was not achieved, the general issues of phase stability in dependence of different temperature-time exposures can be examined. For the intended feasibility study of the novel approach, the powder condition is suitable for further processing by thermal spraying.

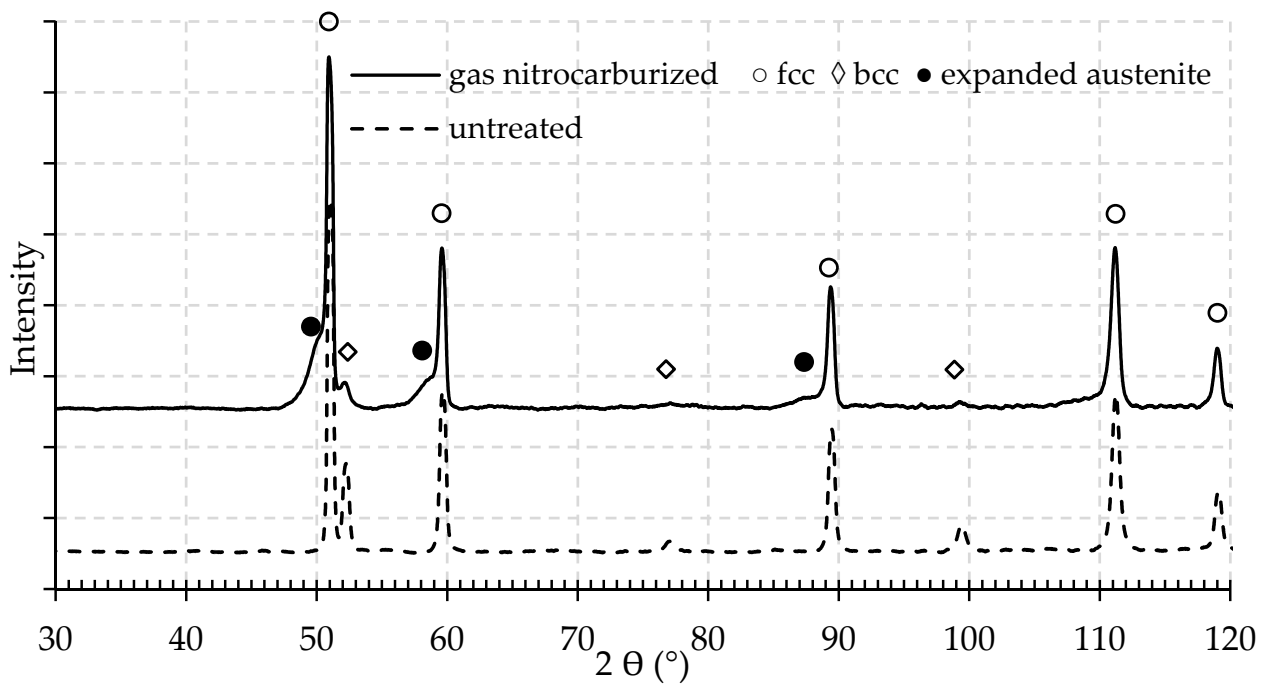

Figure 3. Diffraction diagrams of gas nitrocarburized and untreated AISI 316L powder feedstocks.

\subsection{Coating Characterization}

A similar processing behavior was determined independently of the powder-treatment state. Structurally incorporated impurities occur within the coating, produced by the hardened feedstock material. The differences in the heat load during the thermal-spray processing directly affect the microstructure of the coatings (Figure 4). Within the HVOF coating, the single particles can still be distinguished. The short temperature-time exposure of the HVOF prevents a full melting of the particles. The higher heat load during APS causes a complete melting of the powder and the formation of a lamellar structure. Additionally, the different temperature-time profiles of both of the thermal-spraying processes influence the phase constitution. The use of color etchant Beraha-II allows for a clear separation of the different microstructural domains. For the HVOF and the APS coatings, the presence of the S-phase can clearly be observed, proving a sufficient heat stability. Furthermore, 
the grey appearing parts within the coating's structure can be assigned to the impurities from the powder treatment.
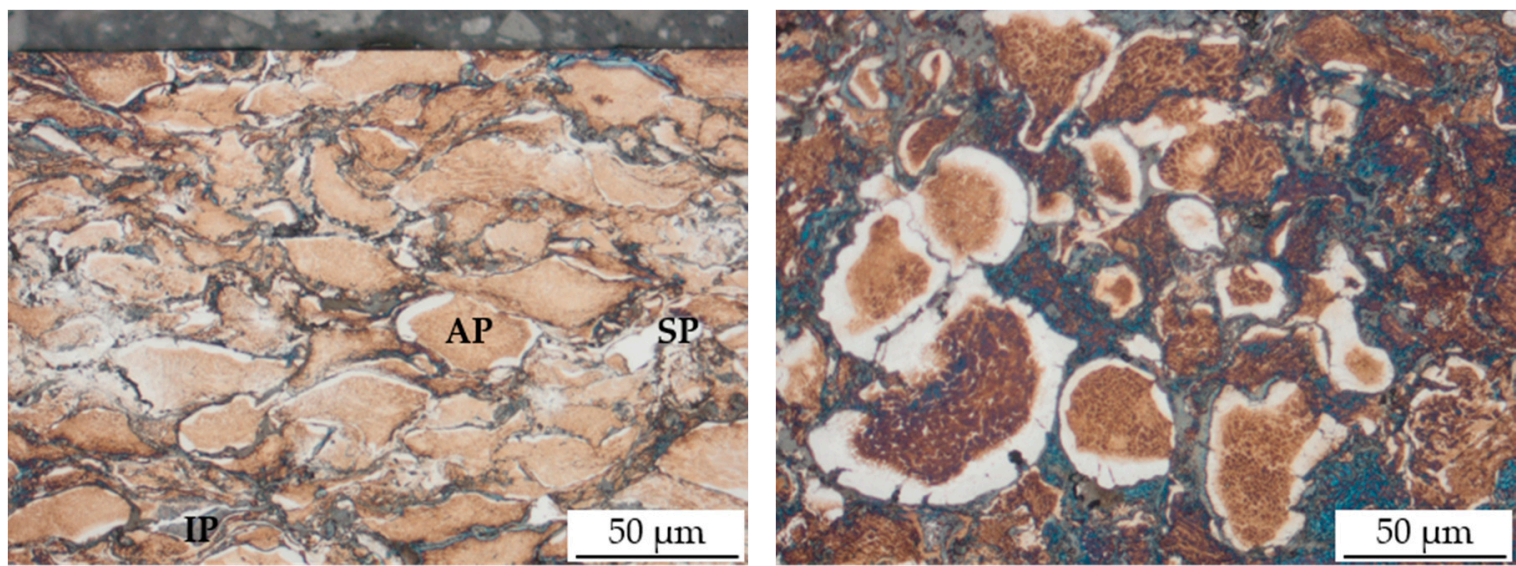

(a) HVOF coating
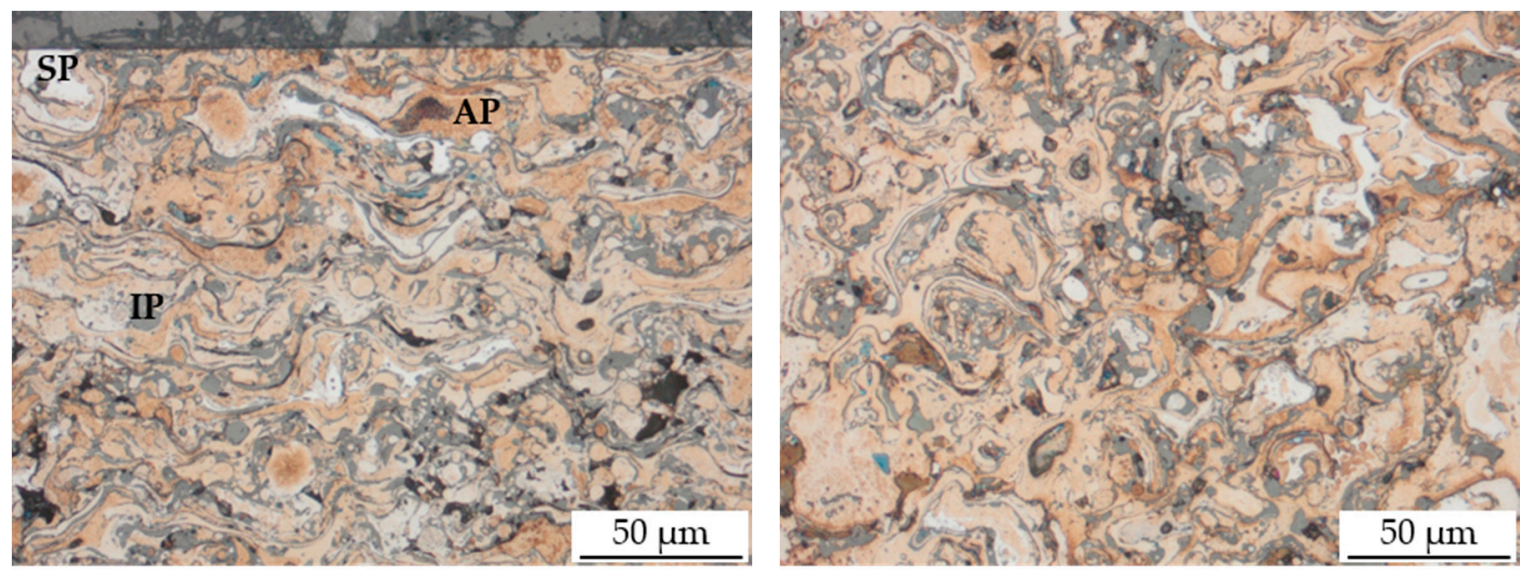

(b) APS coating

Figure 4. Optical-microscopic images of a Beraha-II etched AISI 316L thermal spray coatings in cross-section (left) and top-view (right) with phase declaration (a: high velocity oxy-fuel (HVOF) coating; b: atmospheric plasma spraying (APS) coating; SP-S-phase; AP-austenitic phase; IP-impurity).

The nanoindentation hardness was measured on the cross-sections of the powder and the coatings. The values determined for the different microstructural domains are shown in Table 4 . In comparison to the particle core, the bright layer at the particle's edge exhibits a strongly increased hardness with values above $1100 \mathrm{HV}$ 0.001. The phase selective imaging using the color etchant confirms the presence of different phases, resulting in strong differences in the mechanical properties. In accordance with the mentioned results, the S-phase can be assigned to the bright parts at the particle's edge. Furthermore, the interstitial solvation within the lattice is confirmed.

Table 4. Nanoindentation hardness of the different phase areas of the AISI 316L powder, the HVOF coating, and the APS coating using the gas nitrocarburized feedstock.

\begin{tabular}{ccccccc}
\hline Position & \multicolumn{2}{c}{ Center of Particle (Colored) } & \multicolumn{3}{c}{ Edge of Particle (Bright Layer) } \\
\hline sample & powder & HVOF & APS & powder & HVOF & APS \\
HV 0.001 & 260 & 356 & 336 & 1120 & 1085 & 713 \\
\hline
\end{tabular}

Whereas the optical-microscopic images prove a multiphase state within the HVOF and the APS coating structure, the nanoindentation measurements reveal the impact of the heat load during thermal 
spraying. Although the initial material hardness of the austenitic phase is enhanced because of the different strengthening effects, a decrease in the hardness value of the expanded austenite phase areas was observed. However, the S-phase parts within the HVOF coating still retain a nanoindentation hardness above $1000 \mathrm{HV}$ 0.001. The higher heat load during APS processing causes a stronger decrease. Hence, an influence of the heat load on phase stability is proven.

Additionally, the influence of the heat load on the lattice parameter was investigated. The sections of the diffraction diagrams in Figure 5 exhibit a similar peak for the lattice planes $\{111\}$ of the initial fcc phase at around $51^{\circ}$ for the powder feedstock in untreated state and in both of the resulting coatings. By low temperature gas nitrocarburization, the formation of a broad peak from around $49^{\circ}$ to $51^{\circ}$ in the powder feedstock proves a successful diffusion into the interstices of the lattice. This behavior indicates a gradation of expansion originating from the initial fcc phase.

The lattice expansion reduces during the thermal spraying. An influence of the melting degree of the particles is revealed by the results of the HVOF and APS coatings. Whereas the HVOF coatings show a moderate reduction, the APS coatings exhibit a further decrease in the lattice expansion. The determined hardness values for the S-phase area are reduced similarly. Although the maximum lattice expansion decreases, the peak intensities of both of the coatings exceed the intensity of the gas-nitrocarburized powder within the diffraction angle range from $50.2^{\circ}$ to $50.7^{\circ}$. Furthermore, a significant shift of the main fcc-phase peak to smaller diffraction angels occurs in the case of APS coatings. Hence, a slight expansion of the initial lattice can be observed.

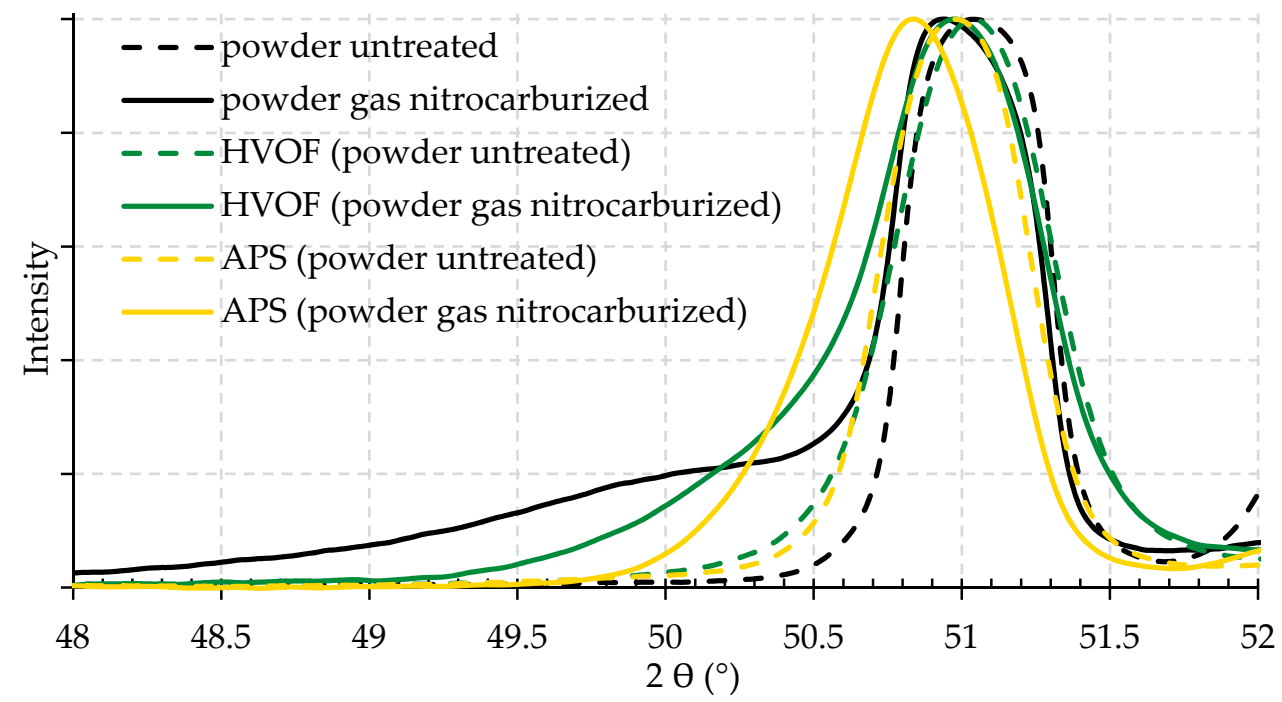

Figure 5. Sections of diffraction diagrams of the untreated and gas nitrocarburized AISI 316L powders and the HVOF and APS coatings.

Within the molten particle's state, diffusion processes occur, which are responsible for the reduction of the lattice expansion. The highest concentration of interstitially dissolved carbon and nitrogen is found on the particle's surface, and decreases with distance. A reduction of the entropy occurs by decreasing the gradient of the elemental concentration due to the dissolution of interstitial elements. However, the short duration time of heat exposure prevents the formation of precipitates. A sufficient heat stability of the S-phase is proven. Furthermore, a homogeneous S-phase formation in the powder feedstock seems to be appropriate for preventing the reduction in the lattice expansion.

Regardless of the heterogeneous treatment state of the powder, as well as the presence of carbon-rich impurities on the particle's edge because of the thermochemical treatment, an increase of wear resistance under abrasive conditions in the scratch tests is achieved for both of the coatings by using gas-nitrocarburized feedstock (Figure 6). In comparison to the untreated reference, the HVOF coatings show the greatest improvement in wear resistance, with a reduction of nearly $50 \%$ in the wear depth. For the APS coatings produced with the hardened feedstock, only a minor 
decrease of wear depth can be achieved. This suggests an influence of the maximum hardness value. Further improvements in the wear resistance can be expected for a homogeneous powder treatment state and the exclusion of impurities.

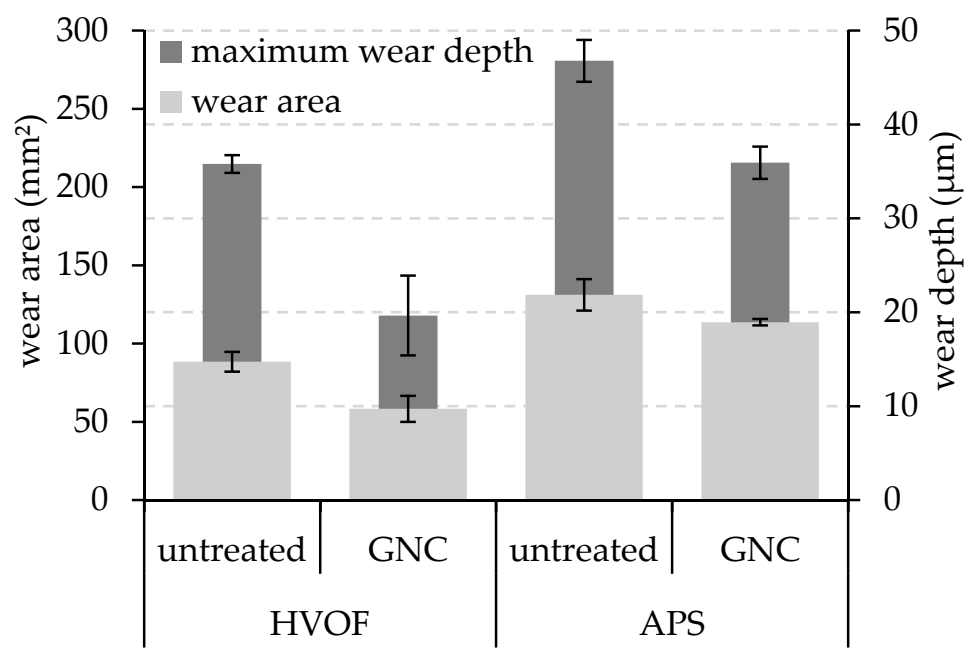

Figure 6. Comparison of the results for wear area and wear depth in scratch tests of HVOF and APS coatings, depending on the treatment state of the powder.

\section{Summary}

A successful solution hardening of 316L powder feedstock for thermal spraying was conducted. Microstructural investigations reveal the formation of a multiphase state. A significant increase in the hardness can be achieved by solution hardening. The novel approach has been investigated for different thermal-spraying processes. A sufficient thermal stability of the metastable S-phase for thermal spraying is proven, whereas the influence of the heat load during processing was determined. Whereas no precipitates are formed, diffusion occurs during processing. This reduces the gradient in the nitrogen and carbon concentration. As a consequence, the maximum lattice expansion and consequently the hardness are reduced for high heat loads. An increase of wear resistance under abrasive load in the scratch test occurs for coatings produced with APS and HVOF. Further improvements can be expected by the exclusion of impurities.

Through the results of the present study, the general feasibility of the novel processing approach is confirmed. Although the metastable S-phase could be successfully formed, adaptions of the hardening process are required in order to achieve a homogeneous powder treatment. Therefore, overlaying diffusion effects and their influence on the material properties have to be studied in more detail. A homogeneous solution hardening of the powder feedstock increases the content of the S-phase within the coating structure. This provides the potential for further improvements of the coating's wear behavior.

Author Contributions: T.L. (Thomas Lindner) conceived and designed the experiments. T.L. (Thomas Lindner) and M.L. performed the experiments, analyzed the data, and wrote the paper. T.L. (Thomas Lampke) directed the research and contributed to the discussion and interpretation of the results.

Funding: The publication costs of this article were funded by the German Research Foundation/DFG and the Technische Universität Chemnitz in the funding program for open access publishing.

Acknowledgments: The authors thank Thomas Mehner for conducting the XRD measurements, and Christel Pönitz for support in the metallographic investigation.

Conflicts of Interest: The authors declare no conflict of interest. 


\section{References}

1. Somers, M.A.J.; Christiansen, T.L. Low temperature surface hardening of stainless steel. In Thermochemical Surface Engineering of Steels; Mittemeijer, E.J., Somers, M.A.J., Eds.; Elsevier: Amsterdam, The Netherlands, 2015; pp. 557-579.

2. Zhao, C.; Li, C.X.; Dong, H.; Bell, T. Low temperature plasma nitrocarburising of AISI 316 austenitic stainless steel. Surf. Coat. Technol. 2005, 191, 195-200.

3. Bell, T. Current status of supersaturated surface engineered S-phase materials. In Key Engineering Materials; Trans Tech Publications: Zurich, Switzerland, 2008; pp. 289-295.

4. Adachi, S.; Ueda, N. Combined plasma carburizing and nitriding of sprayed AISI 316L coating for improved wear resistance. Surf. Coat. Technol. 2014, 259, 44-49. [CrossRef]

5. Nestler, M.C.; Spies, H.; Hermann, K. Production of duplex coatings by thermal spraying and nitriding. Surf. Eng. 1996, 12, 299-302. [CrossRef]

6. Park, G.; Bae, G.; Moon, K.; Lee, C. Effect of plasma nitriding and nitrocarburinzing on HVOF-sprayed stainless steel coatings. J. Therm. Spray Technol. 2013, 22, 1366-1373. [CrossRef]

7. Wielage, B.; Rupprecht, C.; Lindner, T.; Hunger, R. Surface modification of austenitic thermal spray coatings by low-temperature carburization. In Proceedings of the International Thermal Spray Conference \& Exposition, Hamburg, Germany, 27-29 September 2011.

8. Adachi, S.; Ueda, N. Formation of S-phase layer on plasma sprayed AISI 316L stainless steel coating by plasma nitriding at low temperature. Thin Solid Films 2012, 523, 11-14. [CrossRef]

9. Adachi, S.; Ueda, N. Effect of Cold-Spray Conditions Using a Nitrogen Propellant Gas on AISI 316L Stainless Steel-Coating Microstructures. Coatings 2017, 7, 87. [CrossRef]

10. Adachi, S.; Ueda, N. Wear and Corrosion Properties of Cold-Sprayed AISI 316L Coatings Treated by Combined Plasma Carburizing and Nitriding at Low Temperature. Coatings 2018, 8, 456. [CrossRef]

11. Lindner, T.; Mehner, T.; Lampke, T. Surface modification of austenitic thermal-spray coatings by low-temperature nitrocarburizing. In IOP Conf. Series: Materials Science and Engineering; IOP Publishing: Bristol, UK, 2016; Volume 118. [CrossRef]

12. Lindner, T.; Kutschmann, P.; Löbel, M.; Lampke, T. Hardening of HVOF-Sprayed Austenitic Stainless-Steel Coatings by Gas Nitriding. Coatings 2018, 8, 348. [CrossRef]

13. Duan, C.; Shen, Y.; Feng, X.; Chen, C.; Zhang, J. Nitriding of Fe-18Cr-11Mn powders using mechanical alloying method through aerating nitrogen circularly. Mater. Sci. Technol. 2016, 32, 1231-1239. [CrossRef]

14. Gnedovets, A.G.; Ankudinov, A.B.; Zelenskii, V.A.; Kovalev, E.P.; Wisniewska-Weinert, H.; Alymov, M.I. Synthesis of Micron Particles with Fe-Fe4N Core-Shell Structure at Low-Temperature Gaseous Nitriding of Iron Powder in a Stream of Ammonia. Inorg. Mater. Appl. Res. 2016, 7, 303-309. [CrossRef]

15. Li, X.; Sun, Y.; Bell, T. The Stability of the Nitrogen S-phase in Austenitic Stainless Steel. Z. Metallkd. 1999, 90, 901-907.

16. Tschiptschin, A.P.; Nishikawa, A.S.; Varela, L.B.; Pinedo, C.E. Thermal stability of expanded austenite formed on a DC plasma nitride 316L austenitic stainless steel. Thin Solid Films 2017, 644, 156-165. [CrossRef]

17. Li, Y.; Wang, Z.; Wang, L. Surface properties of nitrided layer on AISI 316L austenitic stainless steel produced by high temperature plasma nitriding in short time. Appl. Surf. Sci. 2014, 298, 243-250. [CrossRef]

18. Bottoli, F.; Jellesen, M.S.; Christiansen, T.L.; Winther, G.; Somers, M.A.J. High temperature solution-nitriding and low-temperature nitriding of AISI 316: Effect on pitting potential and crevice corrosion performance. Appl. Surf. Sci. 2018, 431, 24-31. [CrossRef]

19. Wielage, B.; Rupprecht, C.; Lindner, T.; Drehmann, R. Utilisation potential of water-atomised metal powders for thermal spraying. Keram. Z. 2010, 62, 336-339.

(C) 2018 by the authors. Licensee MDPI, Basel, Switzerland. This article is an open access article distributed under the terms and conditions of the Creative Commons Attribution (CC BY) license (http://creativecommons.org/licenses/by/4.0/). 